УДК 351.82:332.122:627.1(571.63-25)

https://doi.org/10.24866/1813-3274/2020-4/118-127

Н. Г. Присекина ${ }^{1}$, Дальневосточный федеральный университет,

г. Владивосток, Россия

E-mail: prisekina.ng@dvfu.ru

Т. А. Соколовская ${ }^{2}$, Дальневосточный федеральный университет,

г. Владивосток, Россия

E-mail: tanyaas1@inbox.ru

\title{
ОТДЕЛЬНЫЕ ОСОБЕННОСТИ ПРАВОВОГО РЕЖИМА СВОБОДНОГО ПОРТА ВЛАДИВОСТОК И ТЕРРИТОРИЙ ОПЕРЕЖАЮЩЕГО СОЦИАЛЬНО-ЭКОНОМИЧЕСКОГО РАЗВИТИЯ ДЛЯ ИНОСТРАННЫХ ИНВЕСТОРОВ
}

Аннотация. Статья посвящена вопросам исследования отдельных особенностей правового регулирования функционирования Свободного порта Владивосток и территорий опережающего социально-экономического развития путем создания благоприятных условий для иностранных инвесторов, вкладывающих свои или заемные средства в ведение предпринимательской деятельности в пределах данных особых зон. Авторы исследуют нормативную базу регулирования деятельности резидентов указанных территориальных зон, а также проводят анализ факторов, препятствующих повышению активности зарубежных инвесторов по осуществлению финансирования российской экономики и развитию Дальнего Востока. Так, в первую очередь проводится анализ истории нормативного регулирования вопроса привлечения иностранных инвестиций в российскую экономику. Первый законодательный акт в данной области в современной истории был принят ещё во время существования СССР. В дальнейшем нормативная база, касающаяся данного вопроса, продолжала расширяться и совершенствоваться. Исследование касается вопроса льготного порядка создания в пределах вышеуказанных зон объектов инфра-

\footnotetext{
${ }^{1}$ Присекина Наталья Геннадьевна, LL.M., кандидат юридических наук, профессор кафедры международного публичного и частного права Юридической школы Дальневосточного федерального университета, партнер и руководитель Дальневосточного отделения юридической компании «Пепеляев Групп», г. Владивосток, Россия.

${ }_{2}^{2}$ Соколовская Татьяна Анатольевна, студентка Юридической школы Дальневосточного федерального университета, г. Владивосток, Россия.

Для ичитирования: Присекина Н. Г., Соколовская Т. А. Отдельные особенности правового режима свободного порта Владивосток и территорий опережающего социально-экономического развития для иностранных инвесторов // Азиатско-Тихоокеанский регион: экономика, политика, право. 2020. № 4. C. 118-127. DOI https://doi.org/10.24866/1813-3274/2020-4/118-127.
}

(C) Присекина Н. Г., Соколовская Т. А., 2020 
структуры, предназначенных для обеспечения деятельности иностранных инвесторов. В частности, проводится анализ нормативного регулирования, устраняющего избыточное административное регулирование и ускоряющего процесс получения необходимых согласований. Кроме того, рассматривается вопрос преференций при предоставлении земельных участков резидентам, в том числе участков, относящихся к лесному фонду. В ходе исследования поднимается тема недостаточного регулирования порядка предоставления земельных участков, отнесённых к ведению Министерства обороны Российской Федерации. Далее исследуется тема обеспечения резидентов с иностранным участием рабочей силой. В этой связи анализируются порядок привлечения иностранной рабочей силы и соотношение данного льготного порядка с привлечением местных работников. Исследование включает также анализ нормативного регулирования материального обеспечения деятельности резидентов с иностранным участием, а именно - порядка таможенного регулирования поставок товаров и материалов из-за рубежа. Рассматривается вопрос предварительной подачи документов для таможенного оформления ввозимых резидентом материалов. Такой порядок упрощает и ускоряет дальнейшее использование ввезенных товаров. По результатам проведённого исследования делается вывод о том, насколько успешно действующее правовое регулирование в указанной сфере выполняет функцию по привлечению иностранного капитала.

Ключевые слова: иностранные инвестиции, Свободный порт Владивосток, территория опережающего социально-экономического развития, развитие Дальнего Востока, резидент, преференции, льготы, развитие инфраструктуры, предоставление земельных участков, снижение административного барьера, привлечение иностранных работников, рабочая сила, таможенное регулирование, земли лесного фонда, Приморский край, Дальний Восток, Российская Федерация. 
Natalia G. Prisekina ${ }^{1}$, Far Eastern Federal University, Vladivostok, Russia E-mail: prisekina.ng@dvfu.ru

Tatyana A. Sokolovskaya ${ }^{2}$, Far Eastern Federal University, Vladivostok, Russia

E-mail: tanyaas1@inbox.ru

\section{CERTAIN PECULIARITIES OF THE LEGAL REGIME OF THE FREE PORT OF VLADIVOSTOK AND ADVANCED SPECIAL ECONOMIC ZONES FOR FOREIGN INVESTORS}

Abstract. The article is devoted to the study of certain peculiarities of legal regulation of the functioning of the Free Port of Vladivostok and advanced special economic zones by creating favorable conditions for foreign investors who invest their own or borrowed fundsin running business within these special zones. The authors examine the legal framework for regulating the activities of residents of these territorial zones, and also analyze factors that impede the increase in the activity of foreign investors in financing the Russian economy and the development of the Far East. First of all, an analysis is made of the history of legal regulation of the issue of attracting foreign investment in the Russian economy. The first legislative act in this area in modern history was adopted during the existence of the USSR. In the future, the legal framework relating to this issue continued to expand and improve. The study addresses the issue of a preferential procedure for creating infrastructure facilities within the above-mentioned zones intended to support the activities of foreign investors. In particular, the analysis of legal regulation is carried out, eliminating excessive administrative regulation and accelerating the process of obtaining the necessary approvals. In addition, the issue of preference when providing land to residents, including plots related to the forest fund, is being considered. The study raises the topic of inadequate regulation of the procedure for the provision of land allocated to the Ministry of Defense of the Russian Federation. Further, the topic of providing residents with foreign participation with work force is investigated. In this regard, the procedure for acceptance of foreign work force and the correlation of this preferential procedure with the involvement of local workers is analyzed. The study also concerns the normative regulation of the material support of the activities of residents with foreign participation, namely, the procedure for customs regulation of deliveries of goods and materials from abroad. The issue of preliminary filing of documents for customs clearance of materials

\footnotetext{
${ }^{1}$ Natalia G. Prisekina, LL.M., Ph.D. in Law, Professor of International Public and Private Law, School of Law, Far Eastern Federal University, Partner and Head of the Far Eastern Office of a law firm "Pepeliaev Group", Vladivostok, Russia.

${ }^{2}$ Tatyana A. Sokolovskaya, student, School of Law, Far Eastern Federal University, Vladivostok, Russia.

For citing: Prisekina N. G., Sokolovskaya T. A. Certain peculiarities of the legal regime of the Free Port of Vladivostok and advanced special economic zones for foreign investors // PACIFIC RIM: Economics, Politics, Law. 2021. No. 4. P. 118-127. DOI https://doi.org/10.24866/1813-3274/2020-4/118-127.
} 
imported by a resident is being considered. Such an order simplifies and speeds up further use of imported goods. Based on the results of the study, a conclusion is drawn on how successful the current legal regulation in this area performs the function of attracting foreign capital.

Key words: foreign investment, Free Port of Vladivostok, advanced special economic zone (ASEZ), development of the Far East, resident, preferences, benefits, infrastructure development, provision of land, lowering administrative barriers, acceptance of foreign workers, work force, customs regulation, forest lands, Primorsky Krai, Far East, Russian Federation.

В условиях глобализации современного мира и тесного переплетения коммерческих связей множества предприятий из различных государств немаловажным аспектом правового регулирования становится регламентация правоотношений в сфере инвестирования иностранными резидентами. И Российская Федерация в данном случае не является исключением.

Ещё во время существования Советского Союза был принят Закон РСФСР от 04.07.1991 №1545-1 «Об иностранных инвестициях в РСФСР» [1]. В данном законе закреплялась норма о том, что иностранные инвестиции, иностранные вложения в советскую экономику пользуются такой же защитой, как и вложения, осуществляемые резидентами РСФСР. При этом правовой режим для иностранных инвестиций и иностранных инвесторов, осуществляющих вложения в российскую экономику, не может быть менее благоприятным, чем режим для имущества и инвестиционной деятельности юридических лиц и граждан РСФСР. Таким образом, государство давало гарантии сохранности иностранных инвестиций, что свидетельствовало о возможности долгосрочных вложений со стороны иностранных резидентов.

Однако уже в 1999 г. был принят новый закон в данной сфере, который действует и в настоящее время. Речь идёт о Федеральном законе от 09.07.1999 №160Ф3 «Об иностранных инвестициях в Российской Федерации» [2]. Данный правовой акт продолжил политику благоприятствования иностранным инвестициям, подтверждая равенство прав иностранных инвесторов и инвесторов-резидентов Российской Федерации.

Вместе с тем, несмотря на то, что принятие закона явилось одним из определяющих факторов интенсификации иностранных инвестиций в российскую экономику, в дальнейшем назрела необходимость создания нормативных предпосылок для повышения инвестиционной привлекательности страны и отдельных её регионов. И в данном случае российский законодатель постарался решить сразу две задачи. С одной стороны, создать для иностранных инвесторов дополнительные условия, способствующие повышению их интереса и принятию положительных 
инвестиционных решений о развитии бизнеса в России. С другой стороны, направить эти дополнительные вливания в наиболее нуждающиеся регионы страны. В частности, на Дальний Восток России.

А каким образом это возможно сделать, каким образом интенсифицировать, ускорить развитие предпринимательства в определённых регионах страны? Путём создания специальных территорий с установлением льготного режима предпринимательства, в том числе и в первую очередь - для организаций с иностранным участием.

Именно в этой связи и появляются Федеральный закон от 29.12.2014 №473-Ф3 «О территориях опережающего социально-экономического развития в Российской Федерации» [3] (далее - Закон о ТОСЭР) и Федеральный закон от 13.07.2015 №212Ф3 «О свободном порте Владивосток» [4] (далее - Закон о СПВ). Необходимо отметить, что Закон о ТОСЭР фактически регулирует создание отдельных территорий с благоприятствующим режимом в масштабах всей страны, в то время как действие Закона о СПВ направлено именно на развитие Приморского края и, как следствие, всего Дальневосточного региона Российской Федерации.

В первую очередь, создание зон с особыми условиями ведения предпринимательской деятельности призвано активизировать вложения в российскую экономику наиболее заинтересованных игроков азиатского региона - Китая, Японии и Республики Корея. В то же время, заинтересованность иностранных инвесторов в финансировании дальневосточной экономики России ограничивается неразвитостью инфраструктуры, недостаточной квалификацией рабочей силы и неопределенностью с поставками необходимого сырья и материалов [5].

Можно говорить о том, что все указанные недостатки, препятствующие иностранным инвестициям, вызваны, в первую очередь, территориальной отдаленностью региона от основных транспортных путей и логистических цепочек, от производителей, поставщиков и рынков сбыта. Именно поэтому предпринимаемые государством меры направлены на нивелирование и минимизацию данных недостатков.

Что касается развития инфраструктуры и размещения её новых объектов, то этот вопрос решается в рамках Закона о ТОСЭР. При этом положения закона направлены на исключение возможности затягивания решения таких вопросов, в том числе путём ускоренного проведения предварительных этапов работ по возведению инфраструктуры. Например, проведение подготовительных работ для дальнейшего строительства объектов инфраструктуры возможно уже на стадии предоставления на экспертизу проектной документации (пункт 6 статьи 26 Закона о ТОСЭР).

Кроме того, для решения поставленной цели Законом о ТОСЭР устанавливаются конкретные сроки проведения тех или иных административных процедур. В частности, срок проведения государственной экологической экспертизы проектной документации объектов инфраструктуры ограничен сорока пятью днями (пункт 2 статьи 27 Закона о ТОСЭР). 
Отдельно законом регламентируются вопросы, касающиеся предоставления земельных участков для размещения объектов инфраструктуры. При этом статьёй 31 Закона о ТОСЭР установлена возможность размещения объектов инфраструктуры на землях лесного фонда. Для этого разрешаются, в том числе, выборочные и сплошные рубки леса.

Не вдаваясь в возможность злоупотребления данной нормой со стороны недобросовестных резидентов территории опережающего развития, хотелось бы отметить один момент, не учтённый в Законе о ТОСЭР. Так, Постановлением Правительства РФ от 25.06.2015 №629 «О создании территории опережающего социально-экономического развития «Надеждинская» [6] на территории муниципальных образований Надеждинский муниципальный район и Владивостокский городской округ создана ТОСЭР «Надеждинская».

При этом с 1952 г. по 1992 г. (в период существования СССР) г. Владивосток был закрытой территорией, а земля как в самом городе, так и в непосредственной близости от него находилась фактически в ведении Министерства обороны СССР. Значительная часть земельных участков, входящих в ТОСЭР «Надеждинская», попрежнему находится под контролем Министерства обороны РФ.

В результате складывается ситуация, при которой, с одной стороны, предоставляется льготный режим для создания и деятельности компаний, в том числе и с иностранным участием. Но, с другой стороны, сохранение статуса земель обороны и отсутствие регулирования данного вопроса в Законе о ТОСЭР приводит к тому, что предоставление земельных участков и их дальнейшее освоение резидентами ТОСЭР становится затруднительным. При этом изменение категории земель может занять значительное время.

Отдельно необходимо отметить, что Законом о СПВ подробно регулируется вопрос о предоставлении земельных участков резидентам данной территории. В частности, статьёй 28 Закона о СПВ оговариваются конкретные максимальные сроки, например, получения градостроительного плана земельного участка, в предоставлении которого заинтересован резидент, а также сроки проведения общественных слушаний, сроки предоставления различных разрешений, в том числе на строительство и на ввод объектов в эксплуатацию. Таким способом на законодательном уровне пытаются устранить административный барьер, зачастую являющийся губительным для реализации перспективных инвестиционных проектов.

Что касается вопроса, связанного с рабочей силой для иностранных резидентов ТОСЭР, то в данном случае законодатель решил его достаточно просто. При дефиците местных квалифицированных сотрудников резидент ТОСЭР имеет преференции по привлечению на льготных условиях на работу иностранных граждан. Для этого в Трудовой кодекс РФ [7] была введена статья 351.5. Несмотря на то, что в данной норме закрепляется приоритет трудоустройства граждан РФ при прочих 
равных условиях с иностранными работниками, предоставленные льготы, касающиеся случаев найма иностранных работников, позволяют усомниться в реализации данного приоритета.

В частности, резиденту ТОСЭР не требуется получение разрешений на привлечение и использование иностранных работников. В свою очередь, разрешение на работу такому иностранному гражданину, привлекаемому резидентом ТОСЭР, выдается без учёта действующих квот.

Таким образом, иностранному резиденту в такой ситуации выгоднее и проще привлечь иностранного сотрудника, уже обладающего необходимой квалификацией, чем нанимать и, скорее всего, обучать местного работника. При этом немаловажным аспектом при выборе в пользу иностранного работника является языковой барьер, существующий между иностранными работодателями и местными работниками.

Далее, касаясь вопросов поставки материалов и сырья для обеспечения деятельности иностранных резидентов СПВ и ТОСЭР, следует отметить, что решение тут также не в пользу местных, отечественных производителей и поставщиков. При исследовании данного аспекта необходимо обратиться к содержанию Закона о СПВ.

Так, в главе 4 указанного закона достаточно подробно описана процедура таможенного оформления товаров, ввозимых на территорию СПВ и используемых резидентами в своей деятельности. Стоит отметить не только акцент на использование процедуры «единого окна», подразумевающей максимальное сокращение времени на проведение всех необходимых административных процедур.

Возможно также предоставление не менее чем за два часа до прибытия груза на таможенную территорию предварительной информации о таком грузе. Под предварительным информированием понимается представление в таможенный орган информации о товарах и транспортных средствах, необходимой для осуществления таможенного, транспортного, санитарно-карантинного, ветеринарного и карантинного фитосанитарного контроля (надзора). Все эти меры направлены на создание режима максимально быстрого, эффективного и комфортного ввоза резидентами товаров для дальнейшего осуществления своей деятельности.

Как видно из вышеизложенного, и Закон о ТОСЭР, и Закон о СПВ призваны создать максимально комфортные условия для осуществления инвестирования, в том числе иностранного. Однако примеры, приведённые в данном исследовании, показывают, что имеются ещё аспекты, требующие дополнительного регулирования, как например, передача прав на земельные участки от Министерства обороны РФ для дальнейшего предоставления резидентам.

Вместе с тем, предпринимаемые государством усилия не приносят тех результатов по привлечению иностранных инвестиций, которые ожидались и планировались при введении данных особенных правил регулирования предпринимательской дея- 
тельности на территории создаваемых особых зон. С одной стороны, иностранные инвестиции на Дальний Восток составляют более четверти всех иностранных инвестиций в российскую экономику. Однако по состоянию на 2019 г. были озвучены следующие цифры: с 2013 г. на Дальний Восток удалось привлечь более 600 млрд руб. частных инвестиций, из которых 80\% (выделено автором) - российские [8].

Таким образом, данные показатели свидетельствуют о том, что первоочередная цель создания ТОСЭР и территории СПВ по привлечению иностранных инвестиций по-прежнему не достигнута. Зарубежные инвесторы не стремятся вкладываться в российскую экономику. Вместо них особенностями и льготами таких специальных территориальных образований пользуются российские предприниматели. В первую очередь, это связано с возможностью получения налоговых льгот, а также упрощённым оформлением прав на земельные участки.

С учётом изложенных факторов стоит признать, что простого нормативного регулирования данной области недостаточно. Необходимо показать потенциальным зарубежным инвесторам готовность российского государства также финансово участвовать в развитии дальневосточного региона.

Полагаем, что для более активного привлечения иностранных инвестиций вполне может потребоваться предварительное деятельное участие федерального центра и местных органов власти, которые самостоятельно и заблаговременно должны создать минимум необходимых условий для развития предпринимательства, а именно - привлекать инвесторов для реализации проектов при наличии уже готовой для этого инфраструктуры, достаточного количества квалифицированных сотрудников, обладающих компетенциями решать поставленные задачи по реализации проектов с иностранным участием, а также при наличии логистических и транспортных возможностей по снабжению территорий СПВ и ТОСЭР необходимыми материалами и сырьём.

\section{Список литературы}

1. Об иностранных инвестициях в РСФСР: закон РСФСР от 04 июля 1991 г. №1545-1 (в ред. от 10.02.1999) // Ведомости Съезда народных депутатов Российской Федерации и Верховного Совета Российской Федерации. - 1991. - 18 июля, № 29. - Ст. 1008 (утратил силу).

2. Об иностранных инвестициях в Российской Федерации : Федеральный закон от 09.07.1999 № 160-Ф3 (в ред. от 31.05.2018) // Собрание законодательства Российской Федерации. - 1999. - 12 июля, № 28. - Ст. 3493.

3. О территориях опережающего социально-экономического развития в Российской Федерации : Федеральный закон от 29.12.2014 № 473-Ф3 (в ред. от 26.07.2019) // Собрание законодательства Российской Федерации. - 2015. - 5 января, № 1 (часть I). - Ст. 26. 
4. О свободном порте Владивосток : федеральный закон от 13.07.2015 № 212Ф3 (в ред. от 26.07.2019) // Собрание законодательства Российской Федерации. 2015. - 20 июля, № 29 (часть I). - Ст. 4338.

5. Левченко, Т. А. Свободный порт Владивосток как фактор привлечения прямых иностранных инвестиций в экономику Дальнего Востока России / Т. А. Левченко, В. В. Хаблак // Общество: политика, экономика, право. - 2016. - № 10. C. 49-52.

6. О создании территории опережающего социально-экономического развития «Надеждинская» : постановление Правительства Российской Федерации от 25.06.2015 № 629 (в ред. от 15.05.2019) // Собрание законодательства Российской Федерации. - 2015. - 6 июня, № 27. - Ст. 4065.

7. Трудовой кодекс Российской Федерации : Федеральный закон от 30 декабря 2001 № 197-Ф3 (в ред. от 16.12.2019) // Собрание законодательства Российской Федерации. - 2002. - 7 января, № 1 (часть I). - Ст. 3.

8. ТОР подтянули инвесторов // Коммерсантъ. Приложение. - 2019. - 24 сентября, № 173. - URL: https://www.kommersant.ru/doc/4096470 (дата обращения: 29.03.2020).

\section{References}

1. On Foreign Investments in the RSFSR: The Law of the RSFSR dated 04.07.1991 No. 1545-1 (as amended on 10.02.1999). Records of the Congress of People's Deputies of the Russian Federation and the Supreme Council of the Russian Federation, 1991, July 18, no. 29. Article 1008 (has lost force). (In Russian).

2. On Foreign Investments in the Russian Federation: Federal Law dated July 9, 1999 No. 160-FZ (as amended on May 31, 2018). Collection of Legislative Acts of the Russian Federation, 1999, July 12, no. 28, art. 3493.

3. On Priority Development Areas (PDA) in the Russian Federation: Federal Law of December 29, 2014 No. 473-FZ (as amended on July 26, 2019). Collection of Legislative Acts of the Russian Federation, 2015, January 5, no. 1 (part I), art. 26.

4. On the Free Port of Vladivostok: Federal Law of July 13, 2015 No. 212-FZ (as amended on July 26, 2019). Collection of Legislative Acts of the Russian Federation, 2015, July 20, no. 29 (part I), art. 4338.

5. Levchenko T. A., Khablak V. V. Svobodnyi port Vladivostok kak faktor privlecheniya pryamykh inostrannykh investitsii v ekonomiku Dal'nego Vostoka Rossii [The Free Port of Vladivostok as a Factor of Foreign Direct Investments Attraction into the Economy of the Russian Far East]. Obshchestvo: politika, ekonomika, pravo, 2016, no. 10, pp. 49-52.

6. On the creation of the territory of advanced social and economic development «Nadezhdinskaya»: Decree of the Government of the Russian Federation of June 25, 
2015 No. 629 (as amended on May 15, 2019). Collection of Legislative Acts of the Russian Federation. 2015, July 6, no. 27, art. 4065.

7. Labor Code of the Russian Federation: Federal Law of December 30, 2001 No. 197-FZ (as amended on December 16, 2019). Collection of Legislative Acts of the Russian Federation, 2002, January 7, no. 1 (part I), art. 3.

8. Advanced Special Economic Zones pulled investors. Kommersant, 2019, September 24, Appendix no. 173. Available at: https://www.kommersant.ru/doc/4096470 (accessed 29 March 2020). (In Russian). 